\title{
Innovative components of sustainable development in construction
}

\author{
Natalia Lazareva, ${ }^{1, *}$ \\ ${ }^{1}$ Moscow State University of Civil Engineering, Yaroslavskoe shosse, 26, Moscow, 129337, Russia
}

\begin{abstract}
The innovative vector of accelerating the development of construction organization involves the creation of an effective innovation system. The use of advanced achievements of science and technology at the corporate level, as the determining factor of competition, increases the requirements for the adaptability of the subsystem of scientific and technical support for construction. This subsystem, due to the transformation of scientific and technical projects into innovative ones, should ensure the progressive and sustainable development of the construction organization, its reliability and stability. Between the elements of the system of investment and construction activities there are various and complex flows of labor, material, technical, energy, information and financial resources, which are described by a large number of direct and reverse links. The totality of the scientific and technical projects of the construction organization, which gradually turn into innovative ones, form an internal innovation cluster, and independent small venture companies, from the nearest external environment of the company, form an external innovation cluster. The article suggests a mechanism for activating and stimulating scientific, technical and innovative activities at the corporate level based on the organization of cluster systems by the method of disaggregation.
\end{abstract}

\section{Introduction}

One of the reasons for not achieving the necessary level of innovative activity in the construction industry is the discrepancy between organizational methods, structures and forms of transfer of innovations. The priority tasks of the state strategy with regard to science and the domestic innovative sector are currently to stimulate the creation and development of an infrastructure for the commercialization of technologies (including corporate level), as well as to promote the strengthening of the positions of those directions and producers that have already proved their competitiveness within the country and on world markets. In this regard, we can assume the possibility of creating a mechanism for transfer of innovations to the construction industry on the basis of new organizational schemes, the genesis of which is the cluster construction methodology and disaggregation technology [1-4].

Proceeding from the fact that investment and construction activity is characterized by interaction between structure, behavior and mode of functioning, it is possible to interpret

\footnotetext{
* Corresponding author: natatous2017@mail.ru
} 
the sustainable development of investment and construction activities as an optimal trajectory that takes into account the various connections between its constituent parts (construction production, its preparation, design, material and technical, personnel, information, investment support, etc.). The optimal development of each of these subsystems can be ensured only within the framework of the overall optimal (equally equal to sustainable) development [5-8].

\section{Theoretical Basis}

As an initial assumption, it is allowed that sustainable development is described as a movement from one state to another. Each state corresponds to a certain level of risk, which plays an important role in the system of interactions with the external environment and internal transformations. This system at the level of an economic entity is its strategy. In this connection, it is necessary to establish the level of risk of the state of investment and construction activity at a given time (as a rule, at control points) [9-12].

As the basic criteria for solving this problem, the following criteria are adopted: the criterion of the highest caution, the criterion of average efficiency, the criterion of controlled risk.

The risk level of the state of investment and construction activity is determined by a variety of factors, such as: prices, organizational forms, financing methods, security methods, etc. Each risk level $R L 1, \ldots, R L m$ must correspond to the strategy $S 1, \ldots, S n$, which are determined variants of decisions related to production and commercial activities.

The level of risk of a specific state of investment and construction activity is related to a specific strategy and leads to the adoption of appropriate decisions. The effectiveness of the strategy depends, of course, on the state of investment and construction activities. Denoting by $S i j$ the effectiveness of the strategy $\mathrm{Si}$ at the level of risk $R L j$, we arrive at the matrix (Table 1).

Table 1. The matrix of strategy and state of investment and construction activities

\begin{tabular}{|c|c|c|}
\hline \multirow{2}{*}{ Strategy } & \multicolumn{2}{|c|}{ State of ICA } \\
\cline { 2 - 3 } & $R L_{1}$ & $R L_{2}, \ldots R L_{m}$ \\
\hline$S_{1}$ & $S_{11}$ & $S_{12} \ldots S_{1 m}$ \\
\hline$S_{2}$ & $S_{21}$ & $S_{22} \ldots S_{2 m}$ \\
\hline. &. &. \\
\hline. &. &. \\
\hline. &. & $S_{n 2} \ldots S_{n m}$ \\
\hline$S_{n}$ & $S_{n 1}$ & \\
\hline
\end{tabular}

Elements of the Sij matrix should quantify the effectiveness of external interaction and internal transformation, corresponding to strategy $i$ and the level of risk in the state of investment and construction activity $\mathrm{j}$. In this regard, the main task is to choose the optimal strategy.

\section{Results and Discussion}

As the basic criteria for solving this problem, we will consider:

1. Criterion of the highest caution.

In the event that the probabilities of the emergence of a separate state of investment and construction activity are unknown, it is necessary to determine for each strategy $S i$ the least efficiency $S_{i j}$ : 


$$
\delta_{i}=\min _{j} S_{i j}
$$

Then, from these n minimum efficiency values, choose the maximum efficiency:

$$
\hat{\delta}=\max _{i} \delta_{i}=\max _{i} \min _{j} S_{i j}
$$

On this basis, a careful strategy $\mathrm{S}^{*}$, characterized by the effectiveness of $\delta$, is chosen, and this efficiency can be achieved regardless of the state of investment and construction activity.

2. Criterion of average efficiency.

In the event that different states of investment and construction activity are equally probable, that is, $p=1 / \mathrm{m}$, then one can calculate the average efficiency of the strategy $\mathrm{Si}$ :

$$
h_{S i}=\frac{1}{m} \sum_{j=1}^{m} S_{i j}
$$

From the obtained $n$ values of the average efficiency $h_{S i}$, the maximum average efficiency:

$$
\hat{h}=\max _{i} h_{S i}
$$

and thus is the best strategy from this point of view $\mathrm{S}^{*}$.

In a more general case, when the probabilities of the emergence of individual states of investment and construction activities are known, that is:

$$
0 \leq p_{j} \leq 1 \text { for } \sum_{j=1}^{m} p_{j}=1
$$

we can average the effectiveness for each strategy:

$$
\sum_{j=1}^{m} p_{j} S_{i j}
$$

The optimal strategy will be the one that corresponds to the largest of the mean values:

$$
\max _{i} \sum_{j=1}^{m} p_{j} S_{i j} .
$$

\section{Criterion of controlled risk.}

Unlike the criterion of the highest caution, the criterion of controlled risk includes the presence of a certain factor of the negative consequences for participants in investment and construction activities. Denoting by $\alpha_{i}$ and $\beta_{i}$, respectively the maximum and minimum effectiveness of the strategy $\mathrm{Si}$, we obtain:

$$
\begin{aligned}
& \alpha_{i}=\max _{j} S_{i j}, \\
& \beta_{i}=\min _{j} S_{i j} .
\end{aligned}
$$

The probability of the most favorable state of investment and construction activity will be denoted by $\lambda$. The average efficiency of the $S i$ strategy is expressed in this case in the form:

$$
q_{i}=\lambda \alpha_{i}+(1-\lambda) \beta_{i}
$$

Now a strategy is chosen in which the efficiency takes the maximum value:

$$
\hat{q}=\max _{i}\left[\lambda \alpha_{i}+(1-\lambda) \beta_{i}\right] .
$$

At present, the concept of sustainable development is based on the use of a criterion of 
controlled (permissible) risk. The first two criteria are included in the system of parameters as additional, specifying, those decisions that were made on the basis of controlled risk.

Specific features of construction production, as well as links with the parameters of sustainable growth in investment and construction activity, indicate that it can be characterized as a technical and economic system in the aggregate of three main functional groups of subsystems: 1) analysis and synthesis; 2) basic and auxiliary production; 3) the result. Each of them includes elements that have specific mechanisms for sustainable growth (Figure 1).

Between the elements of the system of investment and construction activities there are various and complex flows of labor, material, technical, energy, information and financial resources, which are described by a large number of direct and reverse links, giving the investment and construction activity the character of a complex and unified system [13-17]. Detailing the data of interactions with respect to the innovative component made it possible to form a new organizational chart based on the technology of cluster disaggregation.

The technology of cluster disaggregation is the unity of organizational methods, as well as the methods of obtaining, transferring and commercializing innovations, involving a qualitative transformation of the objects of activity through a stage-by-stage organizational transformation of research results obtained at the corporate level, through the first scientific, technical, and then innovative project and the final stage of the formation of an independent small venture company.

The totality of the scientific and technical projects of the construction organization, which gradually turn into innovative ones, form an internal innovation cluster, and independent small venture companies, from the nearest external environment of the company, form an external innovation cluster. It should be pointed out that such isolation from the structure of a large construction company of a small venture company may be accompanied by loss of it, either full or partial control [18-20].

Commercialization may imply the company's implementation not only of its scientific developments, but also of third-party counterparts acquired on various terms (the socalled complete or incomplete innovation project).

Cluster disaggregation in companies focused on new knowledge can be carried out on the basis of three already known types of organizational structures:

1) a project structure in which the project manager can have a wide range of powers to complete his work program with the resources at his disposal.

2 ) the matrix structure, the powers of the project manager in which are limited, and shared with the functional managers.

3 ) the structure in which the project manager does not have any administrative influence on the activities carried out in the functional units within the project, but acts as an observer or expert.

Using these types of organization, the subject of management has two types of impacts on the management object - the innovation cluster: 1) direct (administrative) impacts; 2) corrective actions that change the incorporate conditions for the implementation of the innovation project.

Corrective influences include information, financial, material and technical, legal, personnel and regulatory support. Managing the intensity and nature of immediate and corrective actions, the construction company can provide favorable conditions for the flow of innovative and scientific and technical activities. 


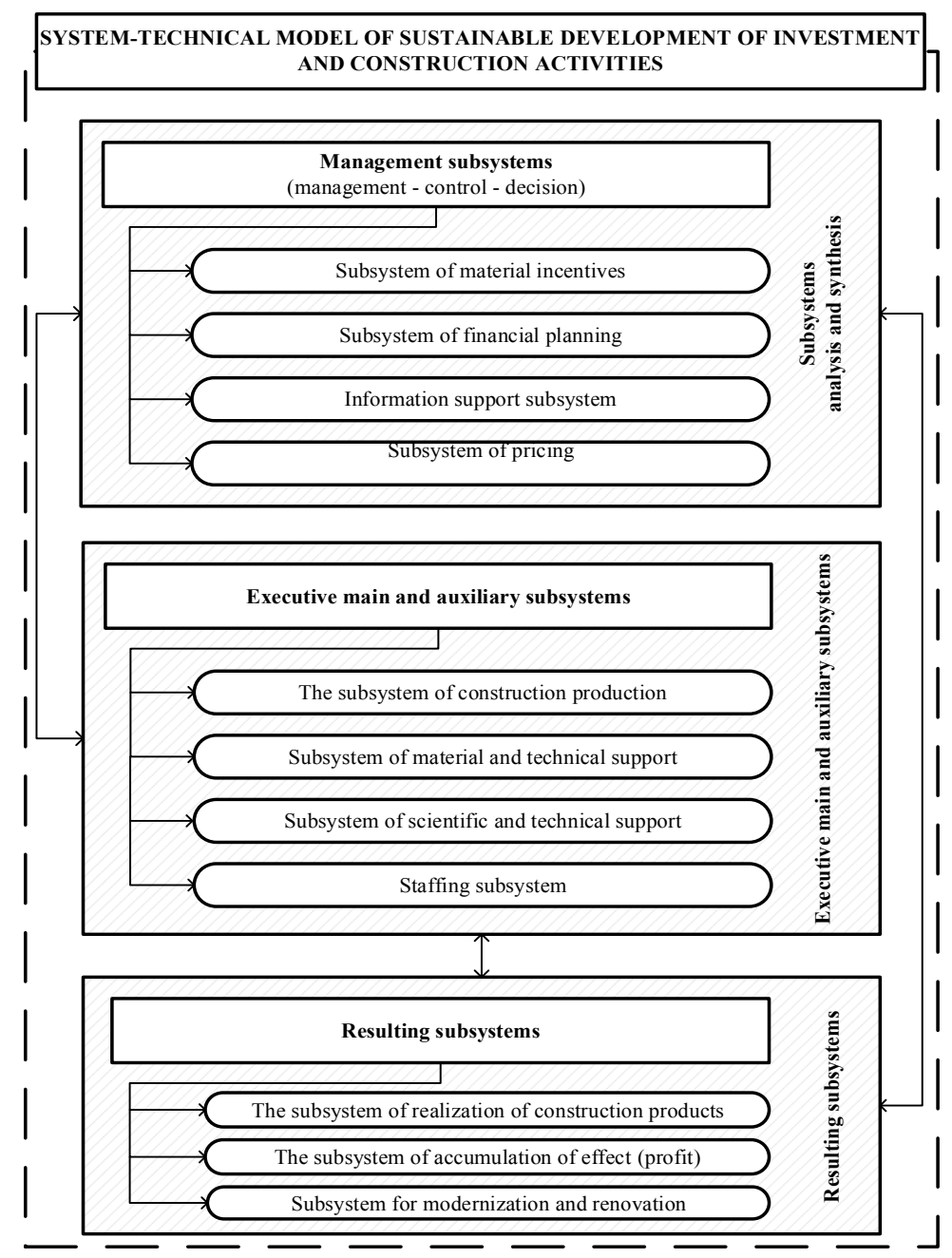

Fig. 1. Functional elements of sustainable development of investment and construction activities at the corporate level

It should be noted that the nature of the interactions will be different in the external and internal innovation clusters. This is due to the organization of impacts on the cluster by the construction company - the initiator of their creation. In the internal innovation cluster, the control actions and their resource saturation are built on the basis of subordination relationships, since scientific and technical and innovative projects are at this stage part of the construction company and are functionally serviced by it (Figure 2).

In an external innovative cluster, the impact of the construction company is mainly associative, since the objects of these impacts are independent small venture firms associated with the parent company or the authorized capital, or the implementation of joint projects, or both (Figure 3). 


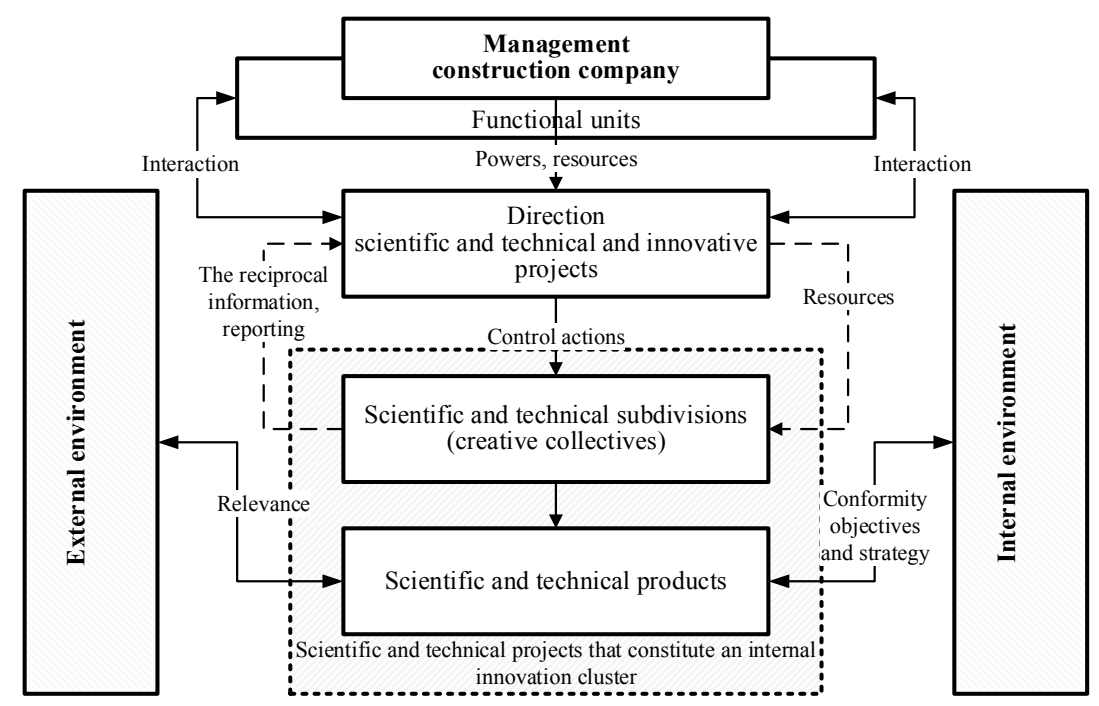

Fig. 2. Scheme of formation of interactions in the internal innovation cluster of a construction company

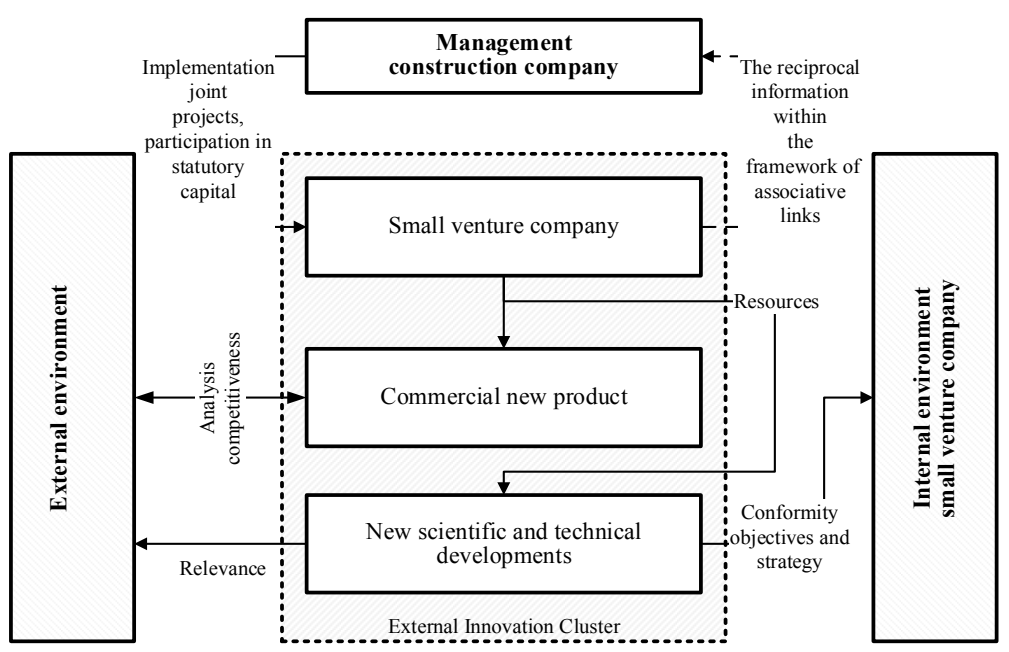

Fig. 3. Scheme of formation of interactions in the internal innovation cluster of a construction company

The basis of the functioning of such firms is their own resources, which can be partially directed to the continuation of scientific and technical developments, which are the basis of their competitiveness. There can be two trends:

1) development of the existing scientific reserve within the framework of a monoproduct company;

2) diversification of scientific and technical developments, which will lead to transformation into a poly-product company.

Scientific and technological progress determines that scientific research and technological developments are an important factor in increasing the competitiveness of construction organizations, and their result is new types of construction products, promising technological methods, and methods for organizing construction production. The effectiveness of scientific and technological progress characterizes the innovative ability, which in turn deter- 
mines the ability to transform new knowledge into production factors.

\section{Conclusions}

Modern trends in the development of science and practice of construction indicate the possibility of regulating the phenomena and processes occurring in the space of investment and construction activities in the direction of realizing the goals of sustainable development. In this connection, the planning, financing and pricing subsystems implement the tasks of providing the building complex at hierarchy levels, maintaining the homeostatic balance of the system, and measuring the efficiency and profitability of production and supply processes.

These subsystems, together with a subsystem of information support, reflect the movement of investment flows, and also identifies the results of investment and construction activities at hierarchy levels. Thus, the planning, financing and pricing subsystems, through the coordinated interaction of their elements, support the optimal intensity of all investment flows in investment and construction activities, which is an important condition for the effective functioning of construction as a technical and economic system.

Between the flows at the entrance and exit of investment and construction activities, close ties are formed, and expenditures can be allowed only to the extent that the sources of income allow, ie, the state of homeostatic equilibrium must be observed. At the same time, the balance of inflow and outflow of investment resources characterizes the relationship between distribution and consumption in the process of expanded reproduction, the final use of construction products.

The proposed mechanism for activation and stimulation of scientific, technical and innovation activities at the corporate level based on the organization of cluster systems by the method of disaggregation allows: 1) to effectively use limited resources; 2) orient them to the fullest satisfaction of the needs of the construction industry; 3 ) promote the competitiveness of construction companies.

\section{References}

1. N. Lazareva. Cluster model of organization of innovative activity at the corporate level in construction [Text]: the thesis of Cand.Tech.Sci. 05.02.22 (2015)

2. S. Sborshikov. Organizational methods of activization of scientific and technical and innovation activities in construction on the basis of territorial and industrial technology parks [Text]: the thesis of Cand.Tech.Sci. 08.00.28 (2000)

3. H. Liu, M Skibniewski, M. Wang. J. Civ. Eng. Manag, 22, 401 (2016)

4. S. Sborshikov. Logistics of Regulatory Impacts in the Investment and Construction Sphere (Theory, Methodology, Practice) [Text]: the thesis of Doc.Econom.Sci. 08.00 .05 (2012)

5. N. Lazareva. Vestnik MGSU, 11, 178 (2015)

6. S. Sborshikov, N. Lazareva. Scientific review 13, 217 (2015)

7. S. Sborshikov, N. Lazareva, Y. Zharov. Vestnik MGSU, 2, 210 (2014)

8. S. Sborshikov, N. Lazareva. Vestnik TGASU, 3, 210 (2014)

9. A. Aleksanin, S. Sborshikov. MATEC Web of Conferences, 86, 05013 (2016)

10. P. Zhuravlev. Vestnik ISTU, 9, 174 (2015)

11. E. Ermolaev. Humanities and Social Sciences, 3, 18 (2013)

12. A. Aleksanin. Vestnik MGSU, 1, 164 (2009) 
13. Y. Zharov. Industrial and Civil Engineering, 5, 69 (2013)

14. N. Shumeyko. Herald of Civil Engineers, 6, 300 (2015)

15. L. Bygballe, M. Ingemansson. Industrial Marketing Management, 43, 512 (2014)

16. K. Jones, B. Martin, P. Winslow. The Structural Engineer, 95, 14 (2017)

17. N. Shumeyko. Estimated contract work in construction, 1, 19 (2016)

18. E. Bahus. Scientific review, 14, 20 (2016)

19. A. Lyapin, V. Lyapin. Scientific review, 8, 251 (2016)

20. A. Shibeika, C. Harty. Construction Management and Economics, 33, 453 (2015) 